Conference Presentation

\title{
Reproducibility of effects of homeopathically potentised Argentum nitricum on the growth of Lemna gibba $L$. in a randomized and blinded bioassay
}

\author{
Vera Majewsky \\ Institute of Complementary Medicine, University of Berne, Insel-Spital, Imhoof-Pavillon, 3010 Bern, \\ Switzerland; Clinic for Animal Reproduction, Faculty of Veterinary Medicine, Freie Universität Berlin \\ Email: vera.majewsky@kikom.ch
}

\begin{abstract}
Background: Reproducibility of basic research investigations in homeopathy is still a challenging issue. A former study reported a significant interaction between date of experiment and treatment effect of Argentum nitricum 14x-30x on the growth rate of duckweed (Lemna gibba L.).

In a reproduction trial with duckweed (Lemna gibba L.) and potencies of gibberellic acid duckweed appeared only then sensitive to treatment with homeopathic potencies of gibberellic acid potencies when the plants were in the growth state of gibbosity.

Aims: This study investigated if formerly observed effects of Argentum nitricum 14x - 30x on growth of Lemna gibba were reproducible and if sensitivity to homeopathic treatment was influenced by the growth state of duckweed.

Methods: Duckweed was grown in potencies of Argentum nitricum $(14 \mathrm{x}-30 \mathrm{x})$ and one time succussed and unsuccussed water control ( $\mathrm{c} 0$ and $\mathrm{c} 1$ ). Area-related growth rate for day 0-7 was determined by a computerised image analysis system. The original study including six independent blinded and randomised experiments each, were repeated one time completely and a second time with 3 experiments. Every repetition experiment was carried out in the same way as in the original study, only time and conductor of experiments were modified. System stability was controlled by systematic negative control (SNC) experiments with the same set-up, but water as the only test substance. All water used in potency and SNC experiments was distilled and autoclaved before use.

Statistical analysis was evaluated with full two-way ANOVA ( $\alpha=5 \%)$, using treatment and experiment number as independent variables and $r_{\text {(area) }}$ for day 0-7 as dependent variable. Data of each experiment was normalised to its mean value to allow a better comparison between experiments. Only if the global ANOVA F-test was significant $(\mathrm{p}<0.05)$ investigated groups were compared with Fisher`s LSD test (protected Fisher`s LSD).
\end{abstract}

Results: The original study observed a significant interaction between treatment and experiment number compared to $\mathrm{c}_{\mathrm{pool}}(\mathrm{c} 0+\mathrm{c} 1)$.Caused to the fact that in the first repetition series a significant

OPEN ACCESS

Cite as: Majewsky V. Reproducibility of effects of homeopathically potentised Argentum nitricum on the growth of Lemna gibba L. in a randomized and blinded bioassay. Proceedings of the XXIX GIRI Meeting; 2015 June 3 - 5; Verona (Italy). Int J High Dilution Res. 2015; 14(2): 7-8. 
treatment difference between c0 and c1 was found, additionally a significant interaction between experiment number and $\mathrm{c} 0$ and $\mathrm{c} 1$, it was not possible to pool $\mathrm{c} 0$ and $\mathrm{c} 1$. All data (original study, as well as repetition series 1 and 2) was evaluated comparing potencies to one time succussed control c1. This new statistical evaluation confirmed the significant interaction between treatment and experiment number for data of the original study $(p=0.0055)$. In the first repetition series a significant treatment effect $(\mathrm{p}=0.016)$ was observed, in the second series no effect. Variability in experiments with Argentum nitricum 14x - 30x was higher than in SNC experiments. The stability of the experimental system was verified by the SNC experiments. An a posteriori subgroup analysis suggests that using a specific growth state of Lemna gibba (gibbosity) seems to be crucial for successful reproduction of the significant interaction of the original study.

Conclusions: With the original study design chosen (disregarding gibbosity of Lemna gibba), results of the original study could not be reproduced. Bioassays for use in homeopathic basic research must carefully consider different physiological states of the test organisms. Variability might be an interesting parameter to investigate effects of homeopathic remedies in basic research.

Financial support: This work was financed in part by grants of Weleda AG (Arlesheim, Switzerland) and Dr. Hauschka Foundation (Boll/Eckwälden, Germany). The sponsors had no influence whatsoever the design, conduct, evaluation and publication of this study.

Keywords: Homeopathy, plants, duckweed, silver nitrate, reproducibility

(C) International Journal of High Dilution Research.

Not for commercial purposes.

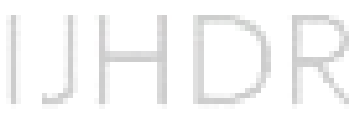

\section{OPEN ACCESS}

Cite as: Majewsky V. Reproducibility of effects of homeopathically potentised Argentum nitricum on the growth of Lemna gibba L. in a randomized and blinded bioassay. Proceedings of the XXIX GIRI Meeting; 2015 June 3 - 5; Verona (Italy). Int J

High Dilution Res. 2015; 14(2): 7-8. 